\title{
Prevenção da cárie dental com aplicações tópicas semestrais de flúor-fosfato acidulado*
}

\section{Dental caries prevention through APF Gel-Tray applications each six months}

\author{
Ilza Leite Pinto**
}

\begin{abstract}
PINTO, I.L. Prevenção da cárie dental com aplicações tópicas semestrais de flúor-fosfato acidulado. Rev. Saúde Pública, 27: 277-90, 1993. Foram analisados os resultados preventivos da aplicação tópica semestral de gel com flúor-fosfato acidulado em 998 crianças, de 6,8 e 10 anos, provenientes de famńlias de baixa renda. Utilizou-se a metodologia de aplicação em massa sem profilaxia prévia desenvolvida no contexto do Programa Nacional de Prevenção da Cárie Dental. Após um ano, constatou-se em localidades sem fluoretação da água de consumo público redução na incidência de cárie da ordem de $31,6 \%$ em crianças de 6 anos, $24,9 \%$ aos 8 anos e $39,5 \%$ aos 10 anos, segundo o índice CPO-S. Nas localidades com flúor na água, as reduçōes foram, respectivamente, de $24,3 \%$, $26,6 \%$ e $27,7 \%$, em todos os casos com significância estatística ao nível de $95 \%$. Face aos resultados positivos e à segurança, custo reduzido e praticidade do método, recomenda-se que os programas de saúde bucal em todos os níveis desenvolvam ação preventiva permanente, abrangente e sem solução de continuidade para as crianças sob sua responsabilidade.
\end{abstract}

Descritores: Fluoretos tópicos. Cárie dentária, prevenção. Levantamentos de saúde bucal.

\section{Introduçáo}

Uma alta prevalência de cárie tem sido usualmente constatada nas crianças brasileiras sem acesso a adequada suplementação de fluoretos, mantendo o país entre os líderes das estatísticas internacionais nesse campo ${ }^{13,17,25}$.

Os diversos métodos preventivos disponíveis, à exceção notável da fluoretação da água de consumo público, têm limitada cobertura ou vêm apresentando débeis resultados. Bochechos com fluoreto de sódio a $0,2 \%$, praticados em programas escolares de vários estados desde o início da década de setenta, não foram capazes de reduzir os índices de cárie dental em nível populacional, por sofrerem freqüentes interrupç̋̃es devidas à irregularidade da presença dos alunos nas escolas ou a problemas de funcionamento das unidades de saúde ${ }^{14,16}$. Somente a partir de $1989 / 90$ os dentifrícios fluoretados passaram a dominar o mercado, inexistindo avaliaçőes específicas quanto a seus resultados em termos coletivos.

\footnotetext{
* Estudo financiado pela Divisão Nacional de Saúde Bucal do Ministério da Saúde - Brasilia, DF - Brasil.

* Condenadora para a área odontológica do Programa Integrado de Saúde Escolar - PISE - da Secretaria da Educação/Fundação Educacional do Distrito Federal Brasilia, DF - Brasil
}

Separatas/Reprints: I.L.Pinto - SQN, 106 - Bloco K - Ap. 302 70742-110 - Brasilia, DF - Brasil
Em 1989, a Divisão Nacional de Saúde Bucal do Ministério da Saúde optou por uma estratégia de base populacional no combate à cárie dental, propondo 0 uso em massa de gel com flúorfosfato acidulado (Gel FFA) duas vezes ao ano em crianças de 6 a 12 anos de idade ${ }^{14}$. O programa foi executado, no Distrito Federal, pela Secretaria de Educação através da Fundação Educacional do DF/Programa Integrado de Saúde Escolar (PISE) ${ }^{23}$, com apoio de outras instituiçōes. Para conhecer os resultados preventivos do método, desenvolveu-se o presente estudo, que prosseguiu durante um ano com as aplicações tópicas de flúor com a mesma metodologia inicial estabelecida pelo PRECAD (Programa Nacional de Prevenção da Cárie Dental) ${ }^{12}$.

Até então largamente utilizado em consultórios particulares, o Gel FFA ganhou viabilidade em saúde pública com a criação de uma nova metodologia de aplicação para grupos numerosos de pessoas e com a eliminação da necessidade de profilaxia prévia 1,6.7,14,20,21. Vários trabalhos científicos asseguram a eficácia das aplicaçð̋es tópicas de Gel FFA, principalmente em áreas sem fluoretação da água 1,2,3,5,6,7,8,11,18,20,21,24.

Com base nos estudos disponíveis, estima-se que o método possibilita uma redução na ocorrência de novas superfícies cariadas entre $23 \%$ e $33 \%^{5,18,19}$. O regime de aplicaçðes semestrais tem demonstrado eficácia adicional em relação ao anual. Os efeitos preventivos permanecem um a 
dois anos após a interrupção das aplicaçð̃es conforme a constatação de estudos recentes ${ }^{18,19}$. O método é considerado seguro $5,9,10,15,18,19$, recomendando-se por precaução manter o paciente em posição ereta, usar moldeiras com espuma absorvente, limitar a quantidade de gel a 2,5 ml por moldeira e, principalmente, fazer o paciente expectorar em abundância após a remoção das moldeiras 9,10 .

Os objetivos do presente trabalho são:

Identificar os efeitos preventivos da aplicação tópica semestral de Gel FFA acidulado, utilizando metodologia coletiva sem profilaxia prévia.

Constatar as condições de segurança do método quanto à sua toxidez com base nas reaçóes apresentadas pelas crianças durante e após as aplicações.

\section{Material e Método}

Foi realizado levantamento epidemiológico de cárie dental - utilizando os índices CPO-D e CPO$S$ de acordo com os critérios estabelecidos pela Organização Mundial da Saúde ${ }^{24}$, em maio de 1990, data do primeiro exame, e em maio de 1991 quando ocorreu o segundo exame. As aplicações semestrais de Gel com flúor efetuaram-se nos meses de maio e novembro de 1990 e maio de 1991, em 998 crianças de baixa renda, matriculadas inicialmente em 16 escolas da rede de ensino de primeiro grau, sendo do Distrito Federal uma escola no Plano Piloto, 4 no bairro do Cruzeiro, 8 na cidade-satélite de Sobradinho, e de Planaltina de Goiás, 3 escolas. Em 1991, quando uma criança transferia-se para uma nova escola, o exame e a aplicação eram aí realizadas. Os alunos foram distribuídos em 12 grupos e em 24 subgrupos considerando os fatores idade, sexo e condição preventiva conforme a discriminação constante da Tabela 1.

As 16 escolas foram selecionadas por serem representativas de localidades situadas em áreas com e sem flúor na água, de acordo com as listagens provenientes da Fundação Educacional do Distrito Federal e da Companhia de Águas e Esgotos (CAESB). Uma vez estabelecidas as respectivas áreas, fez-se a seleção em duas etapas usando a "tabela de números ao acaso". Primeiro foi sorteada a "cidade-satélite" ou região do Plano Piloto e, depois, as escolas que comporiam o estudo dentro de cada uma.

O Plano Piloto e o bairro do Cruzeiro (Distrito Federal) têm fluoretação artificial da água de abastecimento público desde 1962, com uma interrupção constatada no período de 1973 a $1974^{4}$. A cidade-satélite de Sobradinho tem fluoretação contínua desde $1986^{4}$. Para efeitos da aplicação do $\mathrm{Gel}$, as crianças examinadas nessas locali-
Tabela 1. Grupos de escolares, segundo idade, sexo e condição preventiva ao flúor. Distrito Federal, 1990-1991.

\begin{tabular}{|c|c|c|c|c|}
\hline Grupo & Idade & Sexo & $\begin{array}{c}\text { Flúor na } \\
\text { água? }\end{array}$ & GEL FFA? \\
\hline $\begin{array}{l}\mathrm{A} 1 \\
\mathrm{~A} 2 \\
\mathrm{~A} 3\end{array}$ & 6 & $\begin{array}{l}\text { Masculino } \\
\text { Feminino } \\
\text { Ambos }\end{array}$ & não & não \\
\hline $\begin{array}{l}\mathrm{B} 1 \\
\mathrm{~B} 2 \\
\mathrm{~B} 3\end{array}$ & 6 & $\begin{array}{l}\text { Masculino } \\
\text { Feminino } \\
\text { Ambos }\end{array}$ & não & $\operatorname{sim}$ \\
\hline $\begin{array}{l}C_{1} \\
C_{2} \\
C_{3}\end{array}$ & 6 & $\begin{array}{l}\text { Masculino } \\
\text { Feminino } \\
\text { Ambos }\end{array}$ & sim & não \\
\hline $\begin{array}{l}\text { D1 } \\
\text { D2 } \\
\text { D3 }\end{array}$ & 6 & $\begin{array}{l}\text { Masculino } \\
\text { Feminino } \\
\text { Ambos }\end{array}$ & sim & $\operatorname{sim}$ \\
\hline $\begin{array}{l}\text { E1 } \\
\text { E2 } \\
\text { E3 }\end{array}$ & 8 & $\begin{array}{l}\text { Masculino } \\
\text { Feminino } \\
\text { Ambos }\end{array}$ & não & não \\
\hline $\begin{array}{l}\text { F1 } \\
\text { F2 } \\
\text { F3 }\end{array}$ & 8 & $\begin{array}{l}\text { Masculino } \\
\text { Feminino } \\
\text { Ambos }\end{array}$ & nāo & $\operatorname{sim}$ \\
\hline $\begin{array}{l}\text { G1 } \\
\text { G2 } \\
\text { G3 }\end{array}$ & 8 & $\begin{array}{l}\text { Masculino } \\
\text { Feminino } \\
\text { Ambos }\end{array}$ & sim & não \\
\hline $\begin{array}{l}\mathrm{H} 1 \\
\mathrm{H} 2 \\
\mathrm{H} 3\end{array}$ & 8 & $\begin{array}{l}\text { Masculino } \\
\text { Feminino } \\
\text { Ambos }\end{array}$ & $\operatorname{sim}$ & $\operatorname{sim}$ \\
\hline $\begin{array}{l}11 \\
12 \\
13\end{array}$ & 10 & $\begin{array}{l}\text { Masculino } \\
\text { Feminino } \\
\text { Ambos }\end{array}$ & não & não \\
\hline $\begin{array}{l}\mathrm{J} 1 \\
\mathrm{~J} 2 \\
\mathrm{~J} 3\end{array}$ & 10 & $\begin{array}{l}\text { Masculino } \\
\text { Feminino } \\
\text { Ambos }\end{array}$ & não & $\operatorname{sim}$ \\
\hline $\begin{array}{l}\mathrm{K} 1 \\
\mathrm{~K} 2 \\
\mathrm{~K} 3\end{array}$ & 10 & $\begin{array}{l}\text { Masculino } \\
\text { Feminino } \\
\text { Ambos }\end{array}$ & sim & não \\
\hline $\begin{array}{l}\text { L1 } \\
\text { L2 } \\
\text { L3 }\end{array}$ & 10 & $\begin{array}{l}\text { Masculino } \\
\text { Feminino } \\
\text { Ambos }\end{array}$ & sim & sim \\
\hline
\end{tabular}

dades foram consideradas como residentes em área com flúor.

As crianças residentes em Planaltina de Goiás consomem água não fluoretada, justificando-se a inclusão dessa localidade por ser dependente na prática do Distrito Federal e a única onde não há fluoretação (no período do estudo todas as estaçðes de tratamento d'água do Distrito Federal já faziam a adição de flúor).

Uma vez identificadas escolas típicas de cada localidade, foram examinados todos os alunos pre- 
sentes nas idades de 6,8 e 10 anos na data de início do estudo, estratificados segundo o sexo. Iniciaram o estudo 1.440 escolares e 998 o terminaram. Os resultados são apresentados em relação ao número final, considerando que não houve diferença estatisticamente significante tanto no CPO-D quanto no CPO-S entre os dois conjuntos no primeiro exame. A perda de $30,7 \%$ dos inicialmente examinados deveu-se à migração da familia do aluno para outras cidades ou para outras escolas sem comunicação de endereço, e só foi aceita para efeitos do estudo após verificado que a criança não se havia matriculado em outra escola do Distrito Federal ou de Planaltina de Goiás. No período de desenvolvimento do estudo, o Governo do Distrito Federal implantou diversos novos assentamentos populacionais destinados a familias de baixa renda, distribuindo lotes em quantidade.

Não foi levado em consideração o tempo de residência ou o local de nascimento das crianças.

Como método estatístico de análise dos dados foi utilizado o teste " $t$ " de Student para comparação das diferenças das médias, com um nivel de significância de "p $=0,05 "$. Empregou-se o programa "Epi Info, version 5: a word processing DATABASE, and statistic system for epidemiology in microcomputers - Epidemiology Program Office, WHO, Manual 1990".

Utilizou-se Gel FFA (tixotrópico, da SS WHITE) que contém $1,2 \%$ de fluoreto de sódio, e moldeiras duplas com espuma absorvente no fundo, nos tamanhos médio e pequeno. Em cada moldeira foram colocados $2,5 \mathrm{ml}$ de gel. Nenhuma outra medida preventiva foi implementada e não houve qualquer interferência em relação ao acesso ou à oferta de serviços de tratamento clínico odontológico.

Para as aplicaçð̃es tópicas a equipe odontológica contou com a colaboração de professores e da direção de cada escola.

Os exames foram feitos sob luz natural, no pátio das escolas por 3 cirurgiőes-dentistas devidamente calibrados e por 6 técnicos de higiene dental (THD). A metodologia de aplicação em massa foi a desenvolvida pelo PRECAD e descrita em publicação específica ${ }^{12}$, com a seguinte seqüência: a) Organização do local de aplicação, para permitir a circulação contínua das crianças frente à equipe composta por cinco elementos (duas THDs encarregadas da aplicação e do controle de tempo, e professoras para apoio e supervisão das crianças); b) as crianças trazidas de suas salas de aula recebem uma toalha de papel para aparar a saliva à medida em que chegam; c) uma a uma apresentam-se em pé diante da THD que apanha a moldeira dupla já preenchida e efetua a aplicação sem tocar na criança; d) as crianças permanecem em pé, com a cabeça voltada para baixo e a moldeira dupla inserida na boca durante $4 \mathrm{~min}$, sob a observação da segunda THD que controla o tempo e lhes dá o apoio que se fizer necessário orientando-as para nada engolir; e) em seguida, os próprios alunos removem a moldeira e a descartam, expectorando abundantemente ao menos durante $30 \mathrm{seg}$, alem de remover eventuais sobras do gel com toalhas de papel e de receber orientação para nada engolir nos próximos $30 \mathrm{~min}$.

Instruções educativas sobre os benefícios do método, cuidados em relação à higiene oral e orientações precisas sobre como agir durante e após a aplicação, são dadas na sala de aula no momento de trazer as crianças.

\section{Resultados e Discussão}

A Tabela 2, relativa à primeira coleta (ou ao primeiro exame) efetivada em 1990, e a Tabela 3 com a segunda coleta em 1991 apresentam as médias por grupo para o indice CPO-D estratificado em seus quatro componentes: dentes cariados, obturados, extraídos e com extração indicada. Incluem também as médias de dentes sadios e irrompidos (somatório dos dentes atacados pela cárie e sadios).

Informações similares, mas referentes ao índice $\mathrm{CPO}-\mathrm{S}$, que mede as superfícies atacadas pela cárie, sadias e irrompidas, encontram-se nas Tabelas 4 e 5.

Todos os dados primários do estudo, nessas tabelas básicas, estão discriminados grupo por grupo de maneira a corresponder à identificação por sexo e idade vista na Tabela 1.

Os resultados em termos da incidência de cárie, ou seja, das novas cáries surgidas no intervalo de um ano, entre 1990 e 1991, estão resumidos na Tabela 6 em relação aos residentes em localidades nas quais a água de abastecimento público não é fluoretada. Observa-se que, não obstante o período relativamente curto de realização do estudo, as crianças que receberam regularmente aplicações semestrais de Gel FFA desenvolveram menos cáries em termos dos índices CPO-D e CPO-S do que aquelas que não foram beneficiadas pelo método. Em todos os casos as diferenças têm significância estatística com uma confiança ao nível de $95 \%$.

Para o conjunto das crianças (ambos os sexos), houve uma diferença em termos do CPO-D de $35,0 \%$ a favor das que usaram Gel FFA aos 6 anos, de $28,7 \%$ aos 8 anos e de $43,2 \%$ aos 10 anos. Quanto ao CPO-S essas diferenças foram, respectivamente, de $31,6 \%, 24,9 \%$ e $39,5 \%$.

De acordo com a Tabela 7 , nas localidades onde a água de abastecimento é fluoretada, as diferenças se mantém favoravelmente às crianças 
Tabela 2. Indice CPO-D segundo seus componentes, dentes irrompidos e sadios, por grupo de escolares. Distrito Federal, 1990.

\begin{tabular}{|c|c|c|c|c|c|c|c|c|}
\hline \multicolumn{9}{|c|}{ Coleta 1 (médias) } \\
\hline \multirow[t]{2}{*}{ Grupo } & \multirow{2}{*}{$\begin{array}{c}\mathrm{N}^{2} \mathrm{de} \\
\text { Examinados }\end{array}$} & \multicolumn{4}{|c|}{ Dente } & \multirow{2}{*}{$\begin{array}{c}\text { CPO } \\
\bar{D}\end{array}$} & \multirow{2}{*}{$\begin{array}{c}\text { Dente } \\
\text { Irrompido }\end{array}$} & \multirow{2}{*}{$\begin{array}{l}\text { Dente } \\
\text { Sadio }\end{array}$} \\
\hline & & Cariado & Obturado & Extraido & $\begin{array}{l}\text { Extração } \\
\text { Indicada }\end{array}$ & & & \\
\hline $\begin{array}{l}A 1 \\
A 2 \\
A 3\end{array}$ & $\begin{array}{l}46 \\
35 \\
81\end{array}$ & $\begin{array}{l}0,89 \\
0,91 \\
0,90\end{array}$ & $\begin{array}{l}\overline{0,23} \\
0,10\end{array}$ & - & - & $\begin{array}{l}0,89 \\
1,14 \\
1,00\end{array}$ & $\begin{array}{l}4,37 \\
5,23 \\
4,74\end{array}$ & $\begin{array}{l}3,48 \\
4,09 \\
3,74\end{array}$ \\
\hline $\begin{array}{l}\mathrm{B} 1 \\
\mathrm{~B} 2 \\
\mathrm{~B} 3\end{array}$ & $\begin{array}{l}32 \\
34 \\
66\end{array}$ & $\begin{array}{l}0,78 \\
0,82 \\
0,80\end{array}$ & $\begin{array}{l}\overline{0,06} \\
0,03\end{array}$ & $\frac{-}{-}$ & $\begin{array}{l}\overline{0,03} \\
0,02\end{array}$ & $\begin{array}{l}0,78 \\
0,91 \\
0,85\end{array}$ & $\begin{array}{l}5,19 \\
4,41 \\
4,79\end{array}$ & $\begin{array}{l}4,41 \\
3,50 \\
3,94\end{array}$ \\
\hline $\begin{array}{l}c_{1} \\
c_{2} \\
c_{3}\end{array}$ & $\begin{array}{l}51 \\
47 \\
98\end{array}$ & $\begin{array}{l}0,31 \\
0,51 \\
0,41\end{array}$ & $\frac{-}{-}$ & - & $\frac{-}{-}$ & $\begin{array}{l}0,31 \\
0,51 \\
0,41\end{array}$ & $\begin{array}{l}3,94 \\
5,64 \\
4,76\end{array}$ & $\begin{array}{l}3,63 \\
5,13 \\
4,35\end{array}$ \\
\hline $\begin{array}{l}\text { D1 } \\
\text { D2 } \\
D 3\end{array}$ & $\begin{array}{l}40 \\
44 \\
84\end{array}$ & $\begin{array}{l}0,43 \\
0,45 \\
0,44\end{array}$ & $\frac{-}{-}$ & $\frac{-}{-}$ & E & $\begin{array}{l}0,43 \\
0,45 \\
0,44\end{array}$ & $\begin{array}{l}3,45 \\
3,57 \\
3,51\end{array}$ & $\begin{array}{l}3,03 \\
3,11 \\
3,07\end{array}$ \\
\hline $\begin{array}{l}\text { E1 } \\
\text { E2 } \\
\text { E3 }\end{array}$ & $\begin{array}{l}31 \\
32 \\
63\end{array}$ & $\begin{array}{l}2,26 \\
2,06 \\
2,16\end{array}$ & $\begin{array}{l}0,10 \\
0,28 \\
0,19\end{array}$ & $\begin{array}{l}0,13 \\
0,06 \\
0,10\end{array}$ & $\begin{array}{l}0,10 \\
0,13 \\
0,11\end{array}$ & $\begin{array}{l}2,58 \\
2,53 \\
2,56\end{array}$ & $\begin{array}{l}11,10 \\
11,69 \\
11,40\end{array}$ & $\begin{array}{l}8,52 \\
9,16 \\
8,84\end{array}$ \\
\hline $\begin{array}{l}\text { F1 } \\
\text { F2 } \\
\text { F3 }\end{array}$ & $\begin{array}{l}42 \\
38 \\
80\end{array}$ & $\begin{array}{l}2,40 \\
2,39 \\
2,40\end{array}$ & $\begin{array}{l}0,14 \\
0,29 \\
0,21\end{array}$ & $\begin{array}{l}0,07 \\
0,05 \\
0,06\end{array}$ & $\begin{array}{l}0,17 \\
0,42 \\
0,29\end{array}$ & $\begin{array}{l}2,79 \\
3,16 \\
2,96\end{array}$ & $\begin{array}{l}10,98 \\
12,92 \\
11,90\end{array}$ & $\begin{array}{l}8,19 \\
9,76 \\
8,94\end{array}$ \\
\hline $\begin{array}{l}\text { G1 } \\
\text { G2 } \\
\text { G3 }\end{array}$ & $\begin{array}{r}50 \\
54 \\
104\end{array}$ & $\begin{array}{l}0,54 \\
0,89 \\
0,72\end{array}$ & $\begin{array}{l}0,86 \\
0,57 \\
0,71\end{array}$ & - & $\frac{-}{-}$ & $\begin{array}{l}1,40 \\
1,46 \\
1,43\end{array}$ & $\begin{array}{l}10,86 \\
12,06 \\
11,48\end{array}$ & $\begin{array}{r}9,46 \\
10,59 \\
10,05\end{array}$ \\
\hline $\begin{array}{l}\mathrm{H}_{1} \\
\mathrm{H} 2 \\
\mathrm{H} 3\end{array}$ & $\begin{array}{r}46 \\
57 \\
103\end{array}$ & $\begin{array}{l}0,54 \\
0,40 \\
0,47\end{array}$ & $\begin{array}{l}0,78 \\
1,23 \\
1,03\end{array}$ & - & $\begin{array}{l}0,04 \\
0,02 \\
0,03\end{array}$ & $\begin{array}{l}1,37 \\
1,65 \\
1,52\end{array}$ & $\begin{array}{l}11,57 \\
11,98 \\
11,80\end{array}$ & $\begin{array}{l}10,20 \\
10,33 \\
10,27\end{array}$ \\
\hline $\begin{array}{l}11 \\
12 \\
13\end{array}$ & $\begin{array}{l}33 \\
38 \\
71\end{array}$ & $\begin{array}{l}2,09 \\
2,71 \\
2,42\end{array}$ & $\begin{array}{l}0,42 \\
0,32 \\
0,37\end{array}$ & $\begin{array}{l}0,09 \\
0,50 \\
0,31\end{array}$ & $\begin{array}{l}0,21 \\
0,53 \\
0,38\end{array}$ & $\begin{array}{l}2,82 \\
4,05 \\
3,48\end{array}$ & $\begin{array}{l}17,73 \\
20,47 \\
19,20\end{array}$ & $\begin{array}{l}14,91 \\
16,42 \\
15,72\end{array}$ \\
\hline $\begin{array}{l}\mathrm{J} 1 \\
\mathrm{~J} 2 \\
\mathrm{~J} 3\end{array}$ & $\begin{array}{l}36 \\
39 \\
75\end{array}$ & $\begin{array}{l}3,25 \\
3,64 \\
3,45\end{array}$ & $\begin{array}{l}0,22 \\
0,18 \\
0,20\end{array}$ & $\begin{array}{l}0,08 \\
0,13 \\
0,11\end{array}$ & $\begin{array}{l}0,31 \\
1,00 \\
0,67\end{array}$ & $\begin{array}{l}3,86 \\
4,95 \\
4,43\end{array}$ & $\begin{array}{l}17,03 \\
21,56 \\
19,39\end{array}$ & $\begin{array}{l}13,17 \\
16,62 \\
14,96\end{array}$ \\
\hline $\begin{array}{l}\mathrm{K} 1 \\
\mathrm{~K} 2 \\
\mathrm{~K} 3\end{array}$ & $\begin{array}{l}44 \\
48 \\
92\end{array}$ & $\begin{array}{l}0,64 \\
1,31 \\
0,99\end{array}$ & $\begin{array}{l}1,48 \\
2,33 \\
1,92\end{array}$ & $\begin{array}{l}0,23 \\
0,06 \\
0,14\end{array}$ & $\begin{array}{l}0,05 \\
0,04 \\
0,04\end{array}$ & $\begin{array}{l}2,39 \\
3,75 \\
3,10\end{array}$ & $\begin{array}{l}17,64 \\
20,77 \\
19,27\end{array}$ & $\begin{array}{l}15,25 \\
17,02 \\
16,17\end{array}$ \\
\hline $\begin{array}{l}\mathrm{L} 1 \\
\mathrm{~L} 2 \\
\mathrm{L3}\end{array}$ & $\begin{array}{l}43 \\
38 \\
81\end{array}$ & $\begin{array}{l}0,14 \\
0,61 \\
0,36\end{array}$ & $\begin{array}{l}2,09 \\
2,84 \\
2,44\end{array}$ & $\begin{array}{l}\overline{0,03} \\
0,01\end{array}$ & $\begin{array}{l}0,14 \\
0,08 \\
0,11\end{array}$ & $\begin{array}{l}2,37 \\
3,55 \\
2,93\end{array}$ & $\begin{array}{l}15,26 \\
19,47 \\
17,23\end{array}$ & $\begin{array}{l}12,88 \\
15,92 \\
14,31\end{array}$ \\
\hline
\end{tabular}

nas quais as aplicaçð̃es tópicas foram feitas. Os percentuais de redução de cárie observados igualmente têm significância estatística, mas são inferiores àqueles obtidos pelos residentes em cidades sem flúor na água, o que corresponde às expectativas iniciais. As reduções CPO-D são de $24,4 \%$, $29,0 \%$ e $29,0 \%$ aos 6,8 e 10 anos, enquanto segundo o indice CPO-S temos, respectivamente, $24,3 \%, 26,6 \%$ e $27,7 \%$.
Os resultados obtidos aproximam-se daqueles alcançados nos estudos clássicos sobre o uso do Gel FFA, referidos na literatura internacional: a) em comunidades sem fluoretação da água de abastecimento, Bryan e Williams ${ }^{2}$ obtiveram $45 \%$ de redução CPO-D e $28 \%$ CPO-S em crianças de 8 a 12 anos, após um ano de estudo; Ingraham e Williams ${ }^{7}$, em crianças de 6 a 10 anos chegaram a 52\% CPO-D e $41 \%$ CPO-S em média de redução 
Tabela 3. Índice CPO-D segundo seus componentes, dentes irrompidos e sadios, por grupo de escolares. Distrito Federal, 1991.

\begin{tabular}{|c|c|c|c|c|c|c|c|c|}
\hline \multicolumn{9}{|c|}{ Coleta 2 (médias) } \\
\hline \multirow[t]{2}{*}{ Grupo } & \multirow{2}{*}{$\begin{array}{c}N^{2} \text { de } \\
\text { Examinados }\end{array}$} & \multicolumn{4}{|c|}{ Dente } & \multirow{2}{*}{$\begin{array}{c}\text { CPO } \\
- \\
D\end{array}$} & \multirow{2}{*}{$\begin{array}{c}\text { Dente } \\
\text { Irrompido }\end{array}$} & \multirow{2}{*}{$\begin{array}{l}\text { Dente } \\
\text { Sadio }\end{array}$} \\
\hline & & Cariado & Obturado & Extraído & $\begin{array}{l}\text { Extração } \\
\text { Indicada }\end{array}$ & & & \\
\hline $\begin{array}{l}\text { A1 } \\
\text { A2 } \\
\text { A3 }\end{array}$ & $\begin{array}{l}46 \\
35 \\
81\end{array}$ & $\begin{array}{l}1,41 \\
1,40 \\
1,41\end{array}$ & $\begin{array}{l}0,07 \\
0,37 \\
0,20\end{array}$ & $\begin{array}{l}\overline{0,08} \\
0,01\end{array}$ & $\frac{0,02}{0,01}$ & $\begin{array}{l}1,50 \\
1,80 \\
1,63\end{array}$ & $\begin{array}{l}9,30 \\
9,94 \\
9,58\end{array}$ & $\begin{array}{l}7,80 \\
8,14 \\
7,95\end{array}$ \\
\hline $\begin{array}{l}\text { B1 } \\
\text { B2 } \\
\text { B3 }\end{array}$ & $\begin{array}{l}32 \\
34 \\
66\end{array}$ & $\begin{array}{l}1,09 \\
0,88 \\
0,98\end{array}$ & $\begin{array}{l}0,09 \\
0,32 \\
0,21\end{array}$ & $\frac{-}{-}$ & $\begin{array}{l}0,03 \\
0,09 \\
0,06\end{array}$ & $\begin{array}{l}1,22 \\
1,29 \\
1,26\end{array}$ & $\begin{array}{l}8,97 \\
8,71 \\
8,83\end{array}$ & $\begin{array}{l}7,75 \\
7,41 \\
7,58\end{array}$ \\
\hline $\begin{array}{l}c_{1} \\
C_{2} \\
C_{3}\end{array}$ & $\begin{array}{l}51 \\
47 \\
98\end{array}$ & $\begin{array}{l}0,75 \\
1,21 \\
0,97\end{array}$ & $\begin{array}{l}0,20 \\
0,49 \\
0,34\end{array}$ & $\overline{-}$ & $\begin{array}{l}0,04 \\
0,02 \\
0,03\end{array}$ & $\begin{array}{l}0,98 \\
1,72 \\
1,34\end{array}$ & $\begin{array}{r}9,65 \\
10,98 \\
10,29\end{array}$ & $\begin{array}{l}8,67 \\
9,26 \\
8,95\end{array}$ \\
\hline $\begin{array}{l}\text { D1 } \\
\text { D2 } \\
\text { D3 }\end{array}$ & $\begin{array}{l}40 \\
44 \\
84\end{array}$ & $\begin{array}{l}0,93 \\
1,27 \\
1,11\end{array}$ & $\begin{array}{l}0,05 \\
0,02 \\
0,04\end{array}$ & $\overline{-}$ & - & $\begin{array}{l}0,98 \\
1,30 \\
1,14\end{array}$ & $\begin{array}{l}8,95 \\
9,11 \\
9,04\end{array}$ & $\begin{array}{l}7,98 \\
7,82 \\
7,89\end{array}$ \\
\hline $\begin{array}{l}\text { E1 } \\
\text { E2 } \\
\text { E3 }\end{array}$ & $\begin{array}{l}31 \\
32 \\
63\end{array}$ & $\begin{array}{l}2,90 \\
2,56 \\
2,73\end{array}$ & $\begin{array}{l}0,10 \\
0,50 \\
0,30\end{array}$ & $\begin{array}{l}0,16 \\
0,09 \\
0,13\end{array}$ & $\begin{array}{l}0,19 \\
0,28 \\
0,24\end{array}$ & $\begin{array}{l}3,35 \\
3,44 \\
3,40\end{array}$ & $\begin{array}{l}14,55 \\
17,59 \\
16,10\end{array}$ & $\begin{array}{l}11,19 \\
14,16 \\
12,70\end{array}$ \\
\hline $\begin{array}{l}\text { F1 } \\
\text { F2 } \\
\text { F3 }\end{array}$ & $\begin{array}{l}42 \\
38 \\
80\end{array}$ & $\begin{array}{l}2,36 \\
2,50 \\
2,43\end{array}$ & $\begin{array}{l}0,36 \\
0,53 \\
0,44\end{array}$ & $\begin{array}{l}0,07 \\
0,11 \\
0,09\end{array}$ & $\begin{array}{l}0,57 \\
0,66 \\
0,61\end{array}$ & $\begin{array}{l}3,36 \\
3,79 \\
3,56\end{array}$ & $\begin{array}{l}14,62 \\
18,03 \\
16,24\end{array}$ & $\begin{array}{l}11,26 \\
14,24 \\
12,68\end{array}$ \\
\hline $\begin{array}{l}\text { G1 } \\
\text { G2 } \\
\text { G3 }\end{array}$ & $\begin{array}{r}50 \\
54 \\
104\end{array}$ & $\begin{array}{l}0,66 \\
1,19 \\
0,93\end{array}$ & $\begin{array}{l}1,26 \\
1,15 \\
1,20\end{array}$ & $\overline{-}$ & $\begin{array}{l}\overline{0,02} \\
0,01\end{array}$ & $\begin{array}{l}1,92 \\
2,35 \\
2,14\end{array}$ & $\begin{array}{l}13,08 \\
15,94 \\
14,57\end{array}$ & $\begin{array}{l}11,16 \\
13,59 \\
12,42\end{array}$ \\
\hline $\begin{array}{l}\mathrm{H} 1 \\
\mathrm{H} 2 \\
\mathrm{H} 3\end{array}$ & $\begin{array}{r}46 \\
57 \\
103\end{array}$ & $\begin{array}{l}0,70 \\
0,47 \\
0,57\end{array}$ & $\begin{array}{l}1,00 \\
1,77 \\
1,43\end{array}$ & $\frac{-}{-}$ & $\begin{array}{l}0,04 \\
0,02 \\
0,03\end{array}$ & $\begin{array}{l}1,74 \\
2,26 \\
2,03\end{array}$ & $\begin{array}{l}14,59 \\
15,26 \\
14,96\end{array}$ & $\begin{array}{l}12,85 \\
13,00 \\
12,93\end{array}$ \\
\hline $\begin{array}{l}11 \\
12 \\
13\end{array}$ & $\begin{array}{l}33 \\
38 \\
71\end{array}$ & $\begin{array}{l}3,18 \\
3,61 \\
3,41\end{array}$ & $\begin{array}{l}0,70 \\
0,34 \\
0,51\end{array}$ & $\begin{array}{l}0,21 \\
0,74 \\
0,49\end{array}$ & $\begin{array}{l}0,27 \\
0,79 \\
0,55\end{array}$ & $\begin{array}{r}4,36 \\
5,47 \\
.4,96\end{array}$ & $\begin{array}{l}21,12 \\
24,82 \\
23,10\end{array}$ & $\begin{array}{l}16,76 \\
19,34 \\
18,14\end{array}$ \\
\hline $\begin{array}{l}\mathrm{J} 1 \\
\mathrm{~J} 2 \\
\mathrm{~J} 3\end{array}$ & $\begin{array}{l}36 \\
39 \\
75\end{array}$ & $\begin{array}{l}3,61 \\
3,82 \\
3,72\end{array}$ & $\begin{array}{l}0,44 \\
0,41 \\
0,43\end{array}$ & $\begin{array}{l}0,14 \\
0,31 \\
0,23\end{array}$ & $\begin{array}{l}0,58 \\
1,18 \\
0,89\end{array}$ & $\begin{array}{l}4,78 \\
5,72 \\
5,27\end{array}$ & $\begin{array}{l}21,19 \\
26,03 \\
23,71\end{array}$ & $\begin{array}{l}16,42 \\
20,31 \\
18,44\end{array}$ \\
\hline $\begin{array}{l}\mathrm{K} 1 \\
\mathrm{~K} 2 \\
\mathrm{~K} 3\end{array}$ & $\begin{array}{l}44 \\
48 \\
92\end{array}$ & $\begin{array}{l}0,23 \\
0,69 \\
0,47\end{array}$ & $\begin{array}{l}2,23 \\
3,73 \\
3,01\end{array}$ & $\begin{array}{l}0,27 \\
0,10 \\
0,18\end{array}$ & $\begin{array}{l}0,02 \\
0,06 \\
0,04\end{array}$ & $\begin{array}{l}2,75 \\
4,58 \\
3,71\end{array}$ & $\begin{array}{l}21,52 \\
23,67 \\
22,64\end{array}$ & $\begin{array}{l}18,77 \\
19,08 \\
18,93\end{array}$ \\
\hline $\begin{array}{l}\text { L1 } \\
\text { L2 } \\
\text { L3 }\end{array}$ & $\begin{array}{l}43 \\
38 \\
81\end{array}$ & $\begin{array}{l}0,23 \\
0,47 \\
0,35\end{array}$ & $\begin{array}{l}2,26 \\
3,58 \\
2,88\end{array}$ & $\begin{array}{l}\overline{0,03} \\
0,01\end{array}$ & $\begin{array}{l}0,14 \\
0,11 \\
0,12\end{array}$ & $\begin{array}{l}2,63 \\
4,18 \\
3,36\end{array}$ & $\begin{array}{l}21,00 \\
24,47 \\
22,63\end{array}$ & $\begin{array}{l}18,37 \\
20,29 \\
19,27\end{array}$ \\
\hline
\end{tabular}

após dois anos de estudo, mas apenas com uma aplicação anual; Cobb e col$^{3}$ utilizaram aplicações semestrais sempre com resultados positivos embora com dois anos de duração de seus estudos; b) em áreas com fluoretação da água, Melberg e col $^{11}$ com auto-aplicaçð̃es obtiveram $30 \%$ e $35 \%$ CPO-S de redução após um ano trabalhando com a faixa de 9 a 12 anos (neste caso a frequiência foi respectivamente de uma aplicação por 10 e 25 dias consecutivos); Ripa ${ }^{18}$ reconhece que crianças residentes em localidades beneficiadas por água fluoretada devem receber aplicaçð̄es tópicas sempre que apresentem indices elevados de ataque de cárie.

A maioria dos estudos réalizados nos países desenvolvidos envolvem dois anos de trabalhos. Nas condiçбes brasileiras, particularmente nas periferias das grandes cidades, as famílias de baixa renda cos- 
Tabela 4. Indice CPO-S e componentes, superficies irrompidas e sadias, por grupo de escolares. Distrito Federal, 1990.

\begin{tabular}{|c|c|c|c|c|c|c|c|c|}
\hline \multicolumn{9}{|c|}{ Coleta 1 (médias) } \\
\hline \multirow[t]{2}{*}{ Grupo } & \multirow{2}{*}{$\begin{array}{c}N^{2} \text { de } \\
\text { Examinados }\end{array}$} & \multicolumn{4}{|c|}{ Superficie } & \multirow{2}{*}{$\begin{array}{c}\text { CPO } \\
- \\
s\end{array}$} & \multirow{2}{*}{$\begin{array}{l}\text { Superficie } \\
\text { Irrompida }\end{array}$} & \multirow{2}{*}{$\begin{array}{l}\text { Superficie } \\
\text { Sadia }\end{array}$} \\
\hline & & Cariada & Obturada & Extraida & $\begin{array}{l}\text { Extração } \\
\text { Indicada }\end{array}$ & & & \\
\hline $\begin{array}{l}A 1 \\
A 2 \\
A 3\end{array}$ & $\begin{array}{l}46 \\
35 \\
81\end{array}$ & $\begin{array}{l}1,59 \\
1,51 \\
1,56\end{array}$ & $\begin{array}{l}\overline{0,31} \\
0,14\end{array}$ & $\frac{-}{-}$ & $\frac{-}{-}$ & $\begin{array}{l}1,59 \\
1,83 \\
1,69\end{array}$ & $\begin{array}{l}19,46 \\
23,40 \\
21,16\end{array}$ & $\begin{array}{l}17,87 \\
21,57 \\
19,47\end{array}$ \\
\hline $\begin{array}{l}\text { B1 } \\
\text { B2 } \\
\text { B3 }\end{array}$ & $\begin{array}{l}32 \\
34 \\
66\end{array}$ & $\begin{array}{l}0,91 \\
1,38 \\
1,15\end{array}$ & $\begin{array}{l}\overline{0,06} \\
0,03\end{array}$ & $\frac{-}{-}$ & $\begin{array}{l}\overline{0,15} \\
0,08\end{array}$ & $\begin{array}{l}0,91 \\
1,59 \\
1,26\end{array}$ & $\begin{array}{l}23,75 \\
20,09 \\
21,86\end{array}$ & $\begin{array}{l}22,84 \\
18,50 \\
20,61\end{array}$ \\
\hline $\begin{array}{l}\text { C1 } \\
C 2 \\
C 3\end{array}$ & $\begin{array}{l}51 \\
47 \\
98\end{array}$ & $\begin{array}{l}0,61 \\
0,94 \\
0,77\end{array}$ & - & $\frac{-}{-}$ & - & $\begin{array}{l}0,61 \\
0,94 \\
0,77\end{array}$ & $\begin{array}{l}18,08 \\
25,40 \\
21,59\end{array}$ & $\begin{array}{l}17,47 \\
24,47 \\
20,83\end{array}$ \\
\hline $\begin{array}{l}\text { D1 } \\
\text { D2 } \\
\text { D3 }\end{array}$ & $\begin{array}{l}40 \\
44 \\
84\end{array}$ & $\begin{array}{l}0,70 \\
0,82 \\
0,76\end{array}$ & - & $\overline{-}$ & - & $\begin{array}{l}0,70 \\
0,82 \\
0,76\end{array}$ & $\begin{array}{l}15,58 \\
16,18 \\
15,89\end{array}$ & $\begin{array}{l}14,88 \\
15,36 \\
15,13\end{array}$ \\
\hline $\begin{array}{l}\text { E1 } \\
\text { E2 } \\
\text { E3 }\end{array}$ & $\begin{array}{l}31 \\
32 \\
63\end{array}$ & $\begin{array}{l}3,58 \\
3,31 \\
3,44\end{array}$ & $\begin{array}{l}0,10 \\
0,44 \\
0,27\end{array}$ & $\begin{array}{l}0,65 \\
0,31 \\
0,48\end{array}$ & $\begin{array}{l}0,48 \\
0,63 \\
0,56\end{array}$ & $\begin{array}{l}4,81 \\
4,69 \\
4,75\end{array}$ & $\begin{array}{l}48,58 \\
51,19 \\
49,90\end{array}$ & $\begin{array}{l}47,77 \\
46,50 \\
45,16\end{array}$ \\
\hline $\begin{array}{l}F 1 \\
F 2 \\
F 3\end{array}$ & $\begin{array}{l}42 \\
38 \\
80\end{array}$ & $\begin{array}{l}4,38 \\
4,39 \\
4,39\end{array}$ & $\begin{array}{l}0,29 \\
0,55 \\
0,41\end{array}$ & $\begin{array}{l}0,36 \\
0,26 \\
0,31\end{array}$ & $\begin{array}{l}0,81 \\
2,11 \\
1,43\end{array}$ & $\begin{array}{l}5,83 \\
7,32 \\
6,54\end{array}$ & $\begin{array}{l}48,50 \\
57,08 \\
52,58\end{array}$ & $\begin{array}{l}42,67 \\
49,76 \\
46,04\end{array}$ \\
\hline $\begin{array}{l}\text { G1 } \\
\text { G2 } \\
\text { G3 }\end{array}$ & $\begin{array}{r}50 \\
54 \\
104\end{array}$ & $\begin{array}{l}0,94 \\
1,17 \\
1,06\end{array}$ & $\begin{array}{l}1,32 \\
0,78 \\
1,04\end{array}$ & $\frac{-}{-}$ & $\frac{-}{-}$ & $\begin{array}{l}2,26 \\
1,94 \\
2,10\end{array}$ & $\begin{array}{l}47,64 \\
52,87 \\
50,36\end{array}$ & $\begin{array}{l}45,38 \\
50,93 \\
48,26\end{array}$ \\
\hline $\begin{array}{l}\mathrm{H} 1 \\
\mathrm{H} 2 \\
\mathrm{H} 3\end{array}$ & $\begin{array}{r}46 \\
57 \\
103\end{array}$ & $\begin{array}{l}0,61 \\
0,56 \\
0,58\end{array}$ & $\begin{array}{l}1,15 \\
2,07 \\
1,66\end{array}$ & - & $\begin{array}{l}0,22 \\
0,09 \\
0,15\end{array}$ & $\begin{array}{l}1,98 \\
2,72 \\
2,39\end{array}$ & $\begin{array}{l}50,80 \\
52,35 \\
51,66\end{array}$ & $\begin{array}{l}48,83 \\
49,63 \\
49,27\end{array}$ \\
\hline $\begin{array}{l}11 \\
12 \\
13\end{array}$ & $\begin{array}{l}33 \\
38 \\
71\end{array}$ & $\begin{array}{l}3,55 \\
4,24 \\
3,92\end{array}$ & $\begin{array}{l}0,61 \\
0,71 \\
0,66\end{array}$ & $\begin{array}{l}0,45 \\
2,50 \\
1,55\end{array}$ & $\begin{array}{l}1,06 \\
2,58 \\
1,87\end{array}$ & $\begin{array}{r}5,67 \\
10,03 \\
8,00\end{array}$ & $\begin{array}{l}78,88 \\
91,84 \\
85,82\end{array}$ & $\begin{array}{l}73,21 \\
81,82 \\
77,82\end{array}$ \\
\hline $\begin{array}{l}\mathrm{J} 1 \\
\mathrm{~J} 2 \\
\mathrm{~J} 3\end{array}$ & $\begin{array}{l}36 \\
39 \\
75\end{array}$ & $\begin{array}{l}6,06 \\
5,87 \\
5,96\end{array}$ & $\begin{array}{l}0,39 \\
0,38 \\
0,39\end{array}$ & $\begin{array}{l}0,42 \\
0,64 \\
0,53\end{array}$ & $\begin{array}{l}1,50 \\
4,92 \\
3,28\end{array}$ & $\begin{array}{r}8,36 \\
11,82 \\
10,16\end{array}$ & $\begin{array}{l}75,83 \\
97,08 \\
86,88\end{array}$ & $\begin{array}{l}67,47 \\
85,26 \\
76,72\end{array}$ \\
\hline $\begin{array}{l}\mathrm{K} 1 \\
\mathrm{~K} 2 \\
\mathrm{~K} 3\end{array}$ & $\begin{array}{l}44 \\
48 \\
92\end{array}$ & $\begin{array}{l}0,75 \\
1,85 \\
1,33\end{array}$ & $\begin{array}{l}2,02 \\
3,56 \\
2,83\end{array}$ & $\begin{array}{l}1,14 \\
0,31 \\
0,71\end{array}$ & $\begin{array}{l}0,23 \\
0,21 \\
0,22\end{array}$ & $\begin{array}{l}4,14 \\
5,94 \\
5,08\end{array}$ & $\begin{array}{l}78,75 \\
93,27 \\
86,33\end{array}$ & $\begin{array}{l}74,61 \\
87,33 \\
81,25\end{array}$ \\
\hline $\begin{array}{l}\text { L1 } \\
\text { L2 } \\
\text { L3 }\end{array}$ & $\begin{array}{l}43 \\
38 \\
81\end{array}$ & $\begin{array}{l}0,30 \\
0,82 \\
0,54\end{array}$ & $\begin{array}{l}3,14 \\
4,53 \\
3,79\end{array}$ & $\begin{array}{l}\overline{0,13} \\
0,06\end{array}$ & $\begin{array}{l}0,70 \\
0,39 \\
0,56\end{array}$ & $\begin{array}{l}4,14 \\
5,87 \\
4,95\end{array}$ & $\begin{array}{l}64,47 \\
86,84 \\
76,56\end{array}$ & $\begin{array}{l}63,33 \\
80,97 \\
71,60\end{array}$ \\
\hline
\end{tabular}

tumam estar sujeitas a mudanças freqüentes de local de moradia, fazendo com que mesmo estudos longitudinais como este, com um ano de duração, sejam de consecução bastante problemática. Embora um período maior seja desejável, considera-se que o prazo de um ano permite ao pesquisador inferir com razoável aproximação o poder preventivo do método para o caso específico de crianças residentes em um país em desenvolvimento.
Em relação à possível toxidez ocasionada pela ingestão acidental do Gel FFA, conforme o relatado na literatura ${ }^{9,10,15,19}$, no presente estudo não foram constatadas reaçðes negativas ou problemas de naúseas, vômitos ou intoxicação orgânica no universo de crianças atendidas. Esta constatação refere-se, de um lado, à observação atenta da equipe profissional (incluindo cirurgiões-dentistas, THDs e professores de apoio) 
Tabela 5. Índice CPO-S e componentes, superficies irrompidas e sadias, por grupo de escolares. Distrito Federal, 1991.

\begin{tabular}{|c|c|c|c|c|c|c|c|c|}
\hline \multicolumn{9}{|c|}{ Coleta 2 (médias) } \\
\hline \multirow[t]{2}{*}{ Grupo } & \multirow{2}{*}{$\begin{array}{c}\mathrm{N}^{2} \text { de } \\
\text { Examinados }\end{array}$} & \multicolumn{4}{|c|}{ Superficie } & \multirow{2}{*}{$\begin{array}{c}\text { CPO } \\
\bar{s}\end{array}$} & \multirow{2}{*}{$\begin{array}{l}\text { Superficie } \\
\text { Irrompida }\end{array}$} & \multirow{2}{*}{$\begin{array}{l}\text { Superfície } \\
\text { Sadia }\end{array}$} \\
\hline & & Cariada & Obturada & Extraida & $\begin{array}{l}\text { Extraçāo } \\
\text { Indicada }\end{array}$ & & & \\
\hline $\begin{array}{l}A 1 \\
A 2 \\
A 3\end{array}$ & $\begin{array}{l}46 \\
35 \\
81\end{array}$ & $\begin{array}{l}2,39 \\
2,17 \\
2,30\end{array}$ & $\begin{array}{l}0,11 \\
0,43 \\
0,25\end{array}$ & $\begin{array}{l}\overline{0,14} \\
0,06\end{array}$ & $\frac{0,11}{0,06}$ & $\begin{array}{l}2,61 \\
2,74 \\
2,67\end{array}$ & $\begin{array}{l}41,09 \\
43,66 \\
42,20\end{array}$ & $\begin{array}{l}38,48 \\
40,91 \\
39,53\end{array}$ \\
\hline $\begin{array}{l}\text { B1 } \\
\text { B2 } \\
\text { B3 }\end{array}$ & $\begin{array}{l}32 \\
34 \\
66\end{array}$ & $\begin{array}{l}1,38 \\
1,26 \\
1,32\end{array}$ & $\begin{array}{l}0,09 \\
0,50 \\
0,30\end{array}$ & $\frac{-}{-}$ & $\begin{array}{l}0,16 \\
0,44 \\
0,30\end{array}$ & $\begin{array}{l}1,63 \\
2,21 \\
1,92\end{array}$ & $\begin{array}{l}39,91 \\
38,79 \\
39,33\end{array}$ & $\begin{array}{l}38,28 \\
36,59 \\
37,41\end{array}$ \\
\hline $\begin{array}{l}\mathrm{C} 1 \\
\mathrm{C} 2 \\
\mathrm{C} 3\end{array}$ & $\begin{array}{l}51 \\
47 \\
98\end{array}$ & $\begin{array}{l}1,12 \\
1,87 \\
1,48\end{array}$ & $\begin{array}{l}0,29 \\
0,66 \\
0,47\end{array}$ & - & $\begin{array}{l}0,20 \\
0,11 \\
0,15\end{array}$ & $\begin{array}{l}1,61 \\
2,64 \\
2,10\end{array}$ & $\begin{array}{l}42,53 \\
48,19 \\
45,24\end{array}$ & $\begin{array}{l}40,92 \\
45,55 \\
43,14\end{array}$ \\
\hline $\begin{array}{l}\text { D1 } \\
\text { D2 } \\
\text { D3 }\end{array}$ & $\begin{array}{l}40 \\
44 \\
84\end{array}$ & $\begin{array}{l}1,40 \\
2,02 \\
1,73\end{array}$ & $\begin{array}{l}0,08 \\
0,02 \\
0,05\end{array}$ & $\frac{-}{-}$ & $\frac{-}{-}$ & $\begin{array}{l}1,48 \\
2,05 \\
1,77\end{array}$ & $\begin{array}{l}39,68 \\
40,41 \\
40,06\end{array}$ & $\begin{array}{l}38,20 \\
38,36 \\
38,29\end{array}$ \\
\hline $\begin{array}{l}\text { E1 } \\
\text { E2 } \\
\text { E3 }\end{array}$ & $\begin{array}{l}31 \\
32 \\
63\end{array}$ & $\begin{array}{l}5,03 \\
4,13 \\
4,57\end{array}$ & $\begin{array}{l}0,10 \\
0,75 \\
0,43\end{array}$ & $\begin{array}{l}0,81 \\
0,47 \\
0,63\end{array}$ & $\begin{array}{l}0,97 \\
1,41 \\
1,19\end{array}$ & $\begin{array}{l}6,90 \\
6,75 \\
6,83\end{array}$ & $\begin{array}{l}64,19 \\
77,97 \\
71,19\end{array}$ & $\begin{array}{l}57,29 \\
71,22 \\
64,37\end{array}$ \\
\hline $\begin{array}{l}F_{1} \\
F 2 \\
F 3\end{array}$ & $\begin{array}{l}42 \\
38 \\
80\end{array}$ & $\begin{array}{l}3,64 \\
4,18 \\
3,90\end{array}$ & $\begin{array}{l}0,57 \\
0,84 \\
0,70\end{array}$ & $\begin{array}{l}0,36 \\
0,53 \\
0,44\end{array}$ & $\begin{array}{l}2,86 \\
3,29 \\
3,06\end{array}$ & $\begin{array}{l}7,43 \\
8,84 \\
8,10\end{array}$ & $\begin{array}{l}64,69 \\
80,32 \\
72,11\end{array}$ & $\begin{array}{l}57,26 \\
71,47 \\
64,01\end{array}$ \\
\hline $\begin{array}{l}\text { G1 } \\
\text { G2 } \\
\text { G3 }\end{array}$ & $\begin{array}{r}50 \\
54 \\
104\end{array}$ & $\begin{array}{l}1,02 \\
1,65 \\
1,35\end{array}$ & $\begin{array}{l}2,08 \\
1,67 \\
1,87\end{array}$ & $\frac{-}{-}$ & $\begin{array}{l}\overline{0,09} \\
0,05\end{array}$ & $\begin{array}{l}3,10 \\
3,41 \\
3,26\end{array}$ & $\begin{array}{l}57,32 \\
70,52 \\
64,17\end{array}$ & $\begin{array}{l}54,22 \\
67,11 \\
60,91\end{array}$ \\
\hline $\begin{array}{l}\mathrm{H} 1 \\
\mathrm{H} 2 \\
\mathrm{H} 3\end{array}$ & $\begin{array}{r}46 \\
57 \\
103\end{array}$ & $\begin{array}{l}0,96 \\
0,72 \\
0,83\end{array}$ & $\begin{array}{l}1,43 \\
2,95 \\
2,27\end{array}$ & - & $\begin{array}{l}0,22 \\
0,09 \\
0,15\end{array}$ & $\begin{array}{l}2,61 \\
3,75 \\
3,24\end{array}$ & $\begin{array}{l}64,57 \\
67,39 \\
66,13\end{array}$ & $\begin{array}{l}61,96 \\
63,63 \\
62,88\end{array}$ \\
\hline $\begin{array}{l}11 \\
12 \\
13\end{array}$ & $\begin{array}{l}33 \\
38 \\
71\end{array}$ & $\begin{array}{l}5,21 \\
5,58 \\
5,41\end{array}$ & $\begin{array}{l}1,12 \\
0,68 \\
0,89\end{array}$ & $\begin{array}{l}1,06 \\
3,66 \\
2,45\end{array}$ & $\begin{array}{l}1,36 \\
3,84 \\
2,69\end{array}$ & $\begin{array}{r}8,76 \\
13,76 \\
11,44\end{array}$ & $\begin{array}{r}94,97 \\
112,61 \\
104,41\end{array}$ & $\begin{array}{l}86,21 \\
98,84 \\
92,97\end{array}$ \\
\hline $\begin{array}{l}\mathrm{J} 1 \\
\mathrm{~J} 2 \\
\mathrm{~J} 3\end{array}$ & $\begin{array}{l}36 \\
39 \\
75\end{array}$ & $\begin{array}{l}6,19 \\
5,72 \\
5,95\end{array}$ & $\begin{array}{l}0,72 \\
0,82 \\
0,77\end{array}$ & $\begin{array}{l}4,39 \\
1,54 \\
1,13\end{array}$ & $\begin{array}{l}2,83 \\
5,82 \\
4,39\end{array}$ & $\begin{array}{l}10,44 \\
13,90 \\
12,24\end{array}$ & $\begin{array}{r}95,56 \\
118,36 \\
107,41\end{array}$ & $\begin{array}{r}85,11 \\
104,46 \\
95,17\end{array}$ \\
\hline $\begin{array}{l}\mathrm{K} 1 \\
\mathrm{~K} 2 \\
\mathrm{~K} 3\end{array}$ & $\begin{array}{l}44 \\
48 \\
92\end{array}$ & $\begin{array}{l}0,27 \\
0,77 \\
0,53\end{array}$ & $\begin{array}{l}3,16 \\
5,92 \\
4,60\end{array}$ & $\begin{array}{l}1,45 \\
0,52 \\
0,97\end{array}$ & $\begin{array}{l}0,02 \\
0,31 \\
0,17\end{array}$ & $\begin{array}{l}4,91 \\
7,52 \\
6,27\end{array}$ & $\begin{array}{r}96,80 \\
106,94 \\
102,09\end{array}$ & $\begin{array}{l}91,89 \\
99,42 \\
95,82\end{array}$ \\
\hline $\begin{array}{l}\text { L1 } \\
\text { L2 } \\
\text { L3 }\end{array}$ & $\begin{array}{l}43 \\
38 \\
81\end{array}$ & $\begin{array}{l}0,42 \\
1,00 \\
0,69\end{array}$ & $\begin{array}{l}3,58 \\
5,42 \\
4,44\end{array}$ & $\begin{array}{l}\overline{0,13} \\
0,06\end{array}$ & $\begin{array}{l}0,70 \\
0,53 \\
0,62\end{array}$ & $\begin{array}{l}4,70 \\
7,08 \\
5,81\end{array}$ & $\begin{array}{r}94,47 \\
110,92 \\
102,19\end{array}$ & $\begin{array}{r}89,77 \\
103,84 \\
96,37\end{array}$ \\
\hline
\end{tabular}

durante a aplicação e, de outro lado, ao fato de que não foram recebidas queixas das crianças ou de suas famílias em relação ao período pósaplicações nas escolas ou nas residências, após ter sido fornecida orientação específica e feitas perguntas a respeito.

De acordo com a experiência desenvolvida no presente estudo, a aplicação de Gel FFA pode ser considerada segura quando é utilizada a me- todologia coletiva desenvolvida no Programa Nacional de Prevenção da Cárie Dental ${ }^{12,14}$.Isto se deve, provavelmente, às orientações firmes transmitidas aos participantes do Programa quanto aos perigos de ingestão acidental do Gel, à supervisão constante exercida por um membro da equipe durante os quatro minutos em que a moldcira está inserida na boca, à posição ereta com a cabeça abaixada exigida das crianças du- 
Tabela 6. Redução percentual na incidência de cárie dental segundo idade e sexo após um ano de aplicaçôes tópicas semestrais de Gel FFA, em área sem flúor na água de consumo. Planaltina de Goiás, 1990-91*.

\begin{tabular}{|c|c|c|c|c|c|c|}
\hline \multirow{2}{*}{$\begin{array}{c}\text { Idade } \\
\text { em } \\
1990\end{array}$} & \multirow[t]{2}{*}{ Sexo } & \multirow[t]{2}{*}{ Grupo } & \multicolumn{2}{|c|}{ Indice CPO-D médio } & \multicolumn{2}{|c|}{ Índice CPO-S médio } \\
\hline & & & $\begin{array}{l}\text { Incidência } \\
\text { de Cárie }\end{array}$ & $\begin{array}{c}\text { Diferença } \\
(\%)\end{array}$ & $\begin{array}{l}\text { Incidência } \\
\text { de Cárie }\end{array}$ & $\begin{array}{l}\text { Diferença } \\
(\%)\end{array}$ \\
\hline \multirow{6}{*}{6} & \multirow{2}{*}{ Masculino } & A1-sem gel FFA & 0,61 & \multirow{2}{*}{28,12} & 1,02 & \multirow{2}{*}{29,65} \\
\hline & & B1-com gel FFA & 0,44 & & 0,72 & \\
\hline & \multirow{2}{*}{ Feminino } & A2-sem gel FFA & 0,66 & \multirow{2}{*}{41,81} & 0,91 & \multirow{2}{*}{32,44} \\
\hline & & B2-com gel FFA & 0,38 & & 0,62 & \\
\hline & \multirow[b]{2}{*}{ Ambos } & A3-sem gel FFA & 0,63 & \multirow[b]{2}{*}{35,03} & 0,97 & \multirow[b]{2}{*}{31,65} \\
\hline & & B3-com gel FFA & 0,41 & & 0,67 & \\
\hline \multirow{6}{*}{8} & \multirow{2}{*}{ Masculino } & E1-sem gel FFA & 0,77 & \multirow{2}{*}{26,19} & 2,10 & \multirow{2}{*}{23,92} \\
\hline & & F1-com gel FFA & 0,57 & & 1,59 & \\
\hline & \multirow[b]{2}{*}{ Feminino } & E2-sem gel FFA & 0,91 & \multirow[b]{2}{*}{30,31} & 2,06 & \multirow[b]{2}{*}{26,00} \\
\hline & & F2-com gel FFA & 0,63 & & 1,53 & \\
\hline & \multirow{2}{*}{ Ambos } & E3-sem gel FFA & 0,84 & \multirow{2}{*}{28,68} & 2,08 & \multirow{2}{*}{24,86} \\
\hline & & F3-com gel FFA & 0,60 & & 1,56 & \\
\hline \multirow{6}{*}{10} & \multirow{2}{*}{ Masculino } & |1-sem gel FFA & 1,55 & \multirow[b]{2}{*}{40,69} & 3,09 & \multirow[b]{2}{*}{32,60} \\
\hline & & J1-com gel FFA & 0,92 & & 2,08 & \\
\hline & \multirow{2}{*}{ Feminino } & 12-sem gel FFA & 1,42 & \multirow{2}{*}{45,87} & 3,74 & \multirow{2}{*}{44,42} \\
\hline & & J2-com gel FFA & 0,77 & & 2,08 & \\
\hline & \multirow{2}{*}{ Ambos } & |3-sem gel FFA & 1,48 & \multirow{2}{*}{43,20} & 3,44 & \multirow{2}{*}{39,47} \\
\hline & & J3-com gel FFA & 0,84 & & 2,08 & \\
\hline
\end{tabular}

*Todas as diferenças são estatisticamente significantes ao nível de $5 \%$.

Gel FFA - Gel com flúor-fosfato acidulado.

rante a aplicação, à presença da professora no ambiente de trabalho, à expectoração profusa somada à remoção pela própria criança de excessos do gel após a aplicação. Considera-se, também, que as orientações relativas a não ingestão de qualquer alimento ou líquido na meia hora seguinte foram seguidas adequadamente, ajudadas pelo fato de que esse tempo em geral transcorreu dentro do ambiente escolar.

Algumas constatações adicionais emergem da análise dos dados primários mesmo sem se constituirem em pontos centrais do estudo, abrangendo questões como distinções na prevalência de cárie entre localidades com e sem flúor na água ou entre os sexos masculino e feminino.

Pela Tabela 8, vemos que tanto na coleta inicial quanto na realizada em 1991, há menor número de dentes e de superfícies cariadas (C) e obturadas $(\mathrm{O})$ nas crianças residentes em áreas onde a água de consumo público é beneficiada pela adição de flúor à água. Neste caso, o indicador $\mathrm{C}+\mathrm{O}$ é mais apropriado que o CPO-S total considerando que para cada dente extraído ou com extração indicada são computadas todas as superfícies, o que pode, num grupo pouco numeroso como o pequisado, mascarar os resultados. Apesar disto, quando comparamos os índices CPO-D e CPO-S dos grupos de áreas com flúor (C,D,G,H,K,L) e sem flúor (os demais), através das Tabelas 2 a 5 , as diferenças favoráveis aos primeiros se repete. Isto parece demonstrar que 0 fato de residir no Plano Piloto, no bairro do Cruzeiro ou na cidade-satélite de Sobradinho, onde a fluoretação da água é feita (embora mais recente- 
Tabela 7. Redução percentual na incidência de cárie dental segundo idade e sexo após um ano de aplicações tópicas semestrais de Gel FFA, em área com flúor na água de consumo. Distrito Federal, 1990-91*.

\begin{tabular}{|c|c|c|c|c|c|c|}
\hline \multirow{2}{*}{$\begin{array}{l}\text { Idade } \\
\text { em } \\
1990\end{array}$} & \multirow[t]{2}{*}{ Sexo } & \multirow[t]{2}{*}{ Grupo } & \multicolumn{2}{|c|}{ Índice CPO-D médio } & \multicolumn{2}{|c|}{ Índice CPO-S médio } \\
\hline & & & $\begin{array}{l}\text { Incidência } \\
\text { de Cárie }\end{array}$ & $\begin{array}{l}\text { Diferença } \\
(\%)\end{array}$ & $\begin{array}{l}\text { Incidência } \\
\text { de Cárie }\end{array}$ & $\begin{array}{c}\text { Diferença } \\
(\%)\end{array}$ \\
\hline \multirow{6}{*}{6} & \multirow[b]{2}{*}{ Masculino } & C1-sem gel FFA & 0,67 & \multirow[b]{2}{*}{17,50} & 1,00 & \multirow[b]{2}{*}{22,50} \\
\hline & & D1-com gel FFA & 0,55 & & 0,77 & \\
\hline & & C2-sem gel FFA & 1,21 & \multirow{2}{*}{30,66} & 1,70 & \multirow{2}{*}{27,90} \\
\hline & ( & D2-com gel FFA & 0,84 & & 1,23 & \\
\hline & \multirow{2}{*}{ Ambos } & C3-sem gel FFA & 0,93 & \multirow[b]{2}{*}{24,36} & 1,34 & \multirow[b]{2}{*}{24,30} \\
\hline & & D3-com gel FFA & 0,70 & & & \\
\hline \multirow{6}{*}{8} & \multirow{2}{*}{ Masculino } & G1-sem gel FFA & 0,52 & \multirow{2}{*}{28,93} & 0,84 & \multirow{2}{*}{24,95} \\
\hline & & H1-com gel FFA & 0,37 & & 0,63 & \\
\hline & \multirow[b]{2}{*}{ Feminino } & G2-sem gel FFA & 0,89 & \multirow[b]{2}{*}{30,92} & 1,46 & \multirow[b]{2}{*}{29,25} \\
\hline & & H2-com gel FFA & 0,61 & & 1,03 & \\
\hline & \multirow{2}{*}{ Ambos } & G3-sem gel FFA & 0,71 & \multirow{2}{*}{29,05} & 1,16 & \multirow{2}{*}{26,57} \\
\hline & & H3-com gel FFA & 0,50 & & 0,85 & \\
\hline \multirow{6}{*}{10} & \multirow{2}{*}{ Masculino } & K1-sem gel FFA & 0,36 & \multirow{2}{*}{29,65} & 0,77 & \multirow{2}{*}{27,77} \\
\hline & & L1-com gel FFA & 0,26 & & 0,56 & \\
\hline & \multirow{2}{*}{ Feminino } & K2-sem gel FFA & 0,83 & \multirow{2}{*}{24,21} & 1,58 & \multirow{2}{*}{23,54} \\
\hline & & L2-com gel FFA & 0,63 & & 1,21 & \\
\hline & \multirow{2}{*}{ Ambos } & K3-sem gel FFA & 0,61 & \multirow{2}{*}{29,01} & 1,19 & \multirow{2}{*}{27,72} \\
\hline & & L3-com gel FFA & 0,43 & & 0,86 & \\
\hline
\end{tabular}

"Todas as diferenças são estatisticamente significantes ao nível de $5 \%$.

Gel FFA - Gel com flúor-fosfato acidulado.

mente na última), confere uma proteção superior frente ao ataque de cárie em relação à residência em Planaltina de Goiás, onde a água não possui qualquer poder preventivo.

As meninas têm uma prevalência de cárie mais alta, em todos os casos, do que os meninos conforme mostra a Tabela 9 em relação ao índice CPO-D. É um fenômeno que se dá em localidades com e sem flúor na água e que se deve, pelo menos em parte, ao fenômeno conhecido da erupção precoce da dentição no sexo feminino ${ }^{22}$. Tomando-se, como exemplo, a idade de 10 anos no início do estudo (portanto, com 11 anos em 1991), vemos que na área sem flúor as mulheres apresentam na primeira coleta um CPO-D médio de 4,51 contra 3,36 dos homens, enquanto a relação de dentes irrompidos é de 21,02 para
17,36. O índice CPO-S (e o número de superfícies irrompidas) comporta-se de maneira aproximadamente semelhante à do CPO-D quanto à prevalência por sexo, com superioridade para as mulheres. A única exceção, a confirmar a regra geral, está nos Grupos E1 e E2, quando a prevalência é maior no sexo masculino.

As Tabelas 10 e 11 fornecem informações quanto à distribuição das superfícies cariadas e obturadas segundo a face do dente, grupo por grupo.

Considerando-se o total de superfícies $\mathrm{C}+\mathrm{O}$ nas duas coletas e em todos os grupos (não existem diferenças pronunciadas da primeira para a segunda coleta neste aspecto), temos o seguinte padrão básico: $58 \%$ das cavidades situam-se na face oclusal, $3 \%$ na distal, $5 \%$ na mesial, $16 \%$ na vestibular e $18 \%$ na palatina ou lingual. 
Tabela 8. Número médio de dentes e superficies $C+O$, segundo a idade no inicio de estudo, em localidades com e sem flúor na água de consumo público (*). Distrito Federal, 1990-91.

\begin{tabular}{|c|c|c|c|c|c|}
\hline \multirow[t]{2}{*}{$\begin{array}{l}\text { Idade } \\
\text { em } \\
1990\end{array}$} & \multirow[t]{2}{*}{ Localidade } & \multicolumn{2}{|c|}{$\begin{array}{c}N^{2} \text { médio } \\
\text { de dentes } \\
\mathrm{C}+\mathrm{O}\end{array}$} & \multicolumn{2}{|c|}{$\begin{array}{c}\text { Ne médio de } \\
\text { superficie } \\
C+O\end{array}$} \\
\hline & & 1990 & 1991 & 1990 & 1991 \\
\hline \multirow{2}{*}{6} & Com flúor na água & 0,42 & 1,23 & 0,76 & 1,87 \\
\hline & Sem flúor na água & 0,92 & 1,46 & 1,42 & 2,21 \\
\hline \multirow{2}{*}{8} & Com flúor na água & 1,46 & 2,07 & 2,17 & 3,15 \\
\hline & Sem flúor na água & 2,50 & 2,94 & 4,32 & 4,78 \\
\hline \multirow{2}{*}{10} & Com flúor na água & 2,86 & 3,36 & 4,23 & 5,13 \\
\hline & Sem flúor na água & 3,23 & 4,03 & 5,49 & 6,51 \\
\hline
\end{tabular}

*As médias C + O referem-se ao total de crianças examinadas, sem diferenças quanto ao uso ou não de flúor tópico.

$C=$ superficie cariada

$\mathrm{O}=$ superficie obturada cariadas e obturadas, comparado com 0,57 daquelas "com Gel FFA", nos grupos B,D,F,H,J,L. A diferença de 0,59 superfícies $\mathrm{C}+\mathrm{O}$ distribuiu-se da seguinte maneira: 0,25 ou $42 \%$ na face oclusal; 0,04 ou $7 \%$ nas faces proximais e 0,30 ou $51 \%$ nas faces lisas (vestibular e palatina ou lingual). Em relação ao índice CPO-S integral, computando tamberm as faces dos dentes extraídos e com extração indicada, a incidência anual para todos os grupos (6,8 e 10 anos), conforme as Tabelas 2 e 3, foi de 1,60 superfícies nos grupos "sem Gel FFA" e de 1,16 nos demais, com uma diferença de 0,44 por criança.

Ainda com base nas Tabelas 2 a 5, cabe referir os padrões de erupção dentária fornecidos pelo presente estudo para as idades de 6 a 11 anos. Em média as crianças dos quatro grupos examinados aos 6 anos (em 1990) tinham 4,44 dentes erupcionados com 20,08 superficies aos 6 anos; 9,50 dentes e 41,98 superfícies aos 7 anos; 11,65 e 51,17 aos 8 anos; 15,34 e 67,83 aos 9 anos; 18,76 e 83,86 aos 10 anos; 22,99 dentes e 103,88 superfícies aos 11 anos. A proporção de dentes sa-

Tabela 9. Indice CPO-D médio e dentes irrompidos em homens e mulheres, segundo a idade no inicio do estudo. Distrito Federal, 1990-91*.

\begin{tabular}{cccccccc}
\hline $\begin{array}{c}\text { Idade } \\
\begin{array}{c}\text { em } \\
1990\end{array}\end{array}$ & Sexo & \multicolumn{2}{c}{ CPO-D médio em 1990 } & & \multicolumn{2}{c}{ CPO-D médio em 1991 } \\
\cline { 3 - 4 } \cline { 7 - 8 } & & $\begin{array}{c}\text { Área sem } \\
\text { flúor }\end{array}$ & $\begin{array}{c}\text { Área com } \\
\text { flúor }\end{array}$ & & $\begin{array}{c}\text { Área sem } \\
\text { flúor }\end{array}$ & $\begin{array}{c}\text { Área com } \\
\text { flúor }\end{array}$ \\
\hline \multirow{2}{*}{6} & Masculino & $0,84(4,71)$ & $0,36(3,72)$ & & $1,38(9,16)$ & $0,98(9,34)$ \\
& Feminino & $1,03(4,83)$ & $0,48(4,64)$ & & $1,55(9,33)$ & $1,51(10,08)$ \\
& Masculino & $2,70(11,03)$ & $1,39(11,20)$ & & $3,36(14,59)$ & $1,83(13,80)$ \\
8 & Feminino & $2,87(12,36)$ & $1,56(12,02)$ & & $3,63(17,83)$ & $2,30(15,59)$ \\
& Masculino & $3,36(17,36)$ & $2,38(16,46)$ & & $4,58(21,16)$ & $2,69(21,26)$ \\
10 & Feminino & $4,51(21,02)$ & $3,66(20,20)$ & & $5,60(25,43)$ & $4,40(24,02)$ \\
\hline
\end{tabular}

*A média de dentes irrompidos consta entre parêntesis.

No conjunto dos grupos que não receberam aplicação tópica de Gel FFA, para cada dente $\mathrm{C}+\mathrm{O}$ diagnosticou-se um total de 1,55 superfícies na primeira coleta, aumentando para 1,58 na segunda. Nos grupos que receberam o Gel FFA, a média de 1,66 superficies por dentes $\mathrm{C}+\mathrm{O}$ na coleta inicial diminuiu para 1,58 no exame final, um ano após.

A ação preventiva do flúor-fosfato acidulado ocorreu em maior ou menor proporção em todas as faces, mas foi mais elevada nas superfícies lisas dos dentes. No total, as crianças dos grupos "sem Gel FFA" - A,C,E,G,I,K - desenvolveram em média, no prazo de um ano, 1,16 novas superfícies dios diminui de cerca de $85,3 \%$ aos 6 anos para $81,5 \%$ aos 11 , ao passo que as superfícies sadias passam de $94,6 \%$ para $91,6 \%$ nas mesmas faixas.

\section{Conclusరoes e Recomendaçбes}

Em síntese as principais conclusōes preliminares que podem ser tiradas com base nos resultados obtidos no presente estudo são as seguintes:

a) a realização de aplicações tópicas semestrais de Gel FFA de maneira coletiva possibilitou uma 
Tabela 10. Distribuição das superficies cariadas e obturadas segundo a face atacada e o grupo. Distrito Federal, 1990.

\begin{tabular}{|c|c|c|c|c|c|c|c|c|c|c|c|c|c|c|c|}
\hline \multicolumn{16}{|c|}{ Coleta 1} \\
\hline \multirow[t]{3}{*}{ Grupo } & \multirow{3}{*}{$\begin{array}{l}N^{2} \text { de } \\
\text { pessoas } \\
\text { exami- } \\
\text { nadas }\end{array}$} & \multicolumn{7}{|c|}{ Superficies cariadas (código 1) } & \multicolumn{7}{|c|}{ Superflcies obturadas (código 2) } \\
\hline & & \multicolumn{2}{|c|}{ Número Total } & \multirow{2}{*}{$\begin{array}{l}\text { Face } \\
\text { Oclusal }\end{array}$} & \multirow{2}{*}{$\begin{array}{l}\text { Face } \\
\text { Distal }\end{array}$} & \multirow{2}{*}{$\begin{array}{l}\text { Face } \\
\text { Mesial }\end{array}$} & \multirow{2}{*}{$\begin{array}{c}\text { Face } \\
\text { Vestib. }\end{array}$} & \multirow{2}{*}{$\begin{array}{c}\text { Face } \\
\text { Palatino/ } \\
\text { lingual }\end{array}$} & \multicolumn{2}{|c|}{ Número Total } & \multirow{2}{*}{$\begin{array}{l}\text { Face } \\
\text { Oclusal }\end{array}$} & \multirow{2}{*}{$\begin{array}{c}\text { Face } \\
\text { Distal }\end{array}$} & \multirow{2}{*}{$\begin{array}{c}\text { Face } \\
\text { Mesial }\end{array}$} & \multirow{2}{*}{$\begin{array}{l}\text { Face } \\
\text { Vestib. }\end{array}$} & \multirow{2}{*}{$\begin{array}{c}\text { Face } \\
\text { Palatino } \\
\text { lingual }\end{array}$} \\
\hline & & Dentes & Superf. & & & & & & Dentes & Superf. & & & & & \\
\hline A1 & 46 & 41 & 73 & 39 & 0 & 0 & 20 & 14 & 0 & 0 & 0 & 0 & 0 & 0 & 0 \\
\hline A2 & 35 & 32 & 53 & 29 & 0 & 1 & 9 & 14 & 18 & 11 & 4 & 0 & 0 & 1 & 6 \\
\hline$A 3$ & 81 & 73 & 126 & 68 & 0 & 1 & 29 & 28 & 18 & 11 & 4 & 0 & 0 & 1 & 6 \\
\hline B1 & 32 & 25 & 29 & 25 & 0 & 0 & 2 & 2 & 0 & 0 & 0 & 0 & 0 & 0 & 0 \\
\hline B2 & 34 & 28 & 47 & 26 & 0 & 1 & 7 & 13 & 2 & 2 & 2 & 0 & 0 & 0 & 0 \\
\hline B3 & 66 & 53 & 76 & 51 & 0 & 1 & 9 & 15 & 2 & 2 & 2 & 0 & 0 & 0 & 0 \\
\hline$c_{1}$ & 51 & 16 & 31 & 15 & 0 & 5 & 8 & 3 & 0 & 0 & 0 & 0 & 0 & 0 & 0 \\
\hline $\mathrm{C} 2$ & 47 & 24 & 44 & 22 & 0 & 2 & 12 & 8 & 0 & 0 & 0 & 0 & 0 & 0 & 0 \\
\hline $\mathrm{C3}$ & 98 & 40 & 75 & 37 & 0 & 7 & 20 & 11 & 0 & 0 & 0 & 0 & 0 & 0 & 0 \\
\hline D1 & 40 & 97 & 28 & 15 & 0 & 0 & 6 & 7 & 0 & 0 & 0 & 0 & 0 & 0 & 0 \\
\hline D2 & 44 & 20 & 36 & 20 & 0 & 0 & 11 & 5 & 0 & 0 & 0 & 0 & 0 & 0 & 0 \\
\hline D3 & 84 & 37 & 64 & 35 & 0 & 0 & 17 & 12 & 0 & 0 & 0 & 0 & 0 & 0 & 0 \\
\hline $\mathrm{E}_{1}$ & 31 & 70 & 111 & 66 & 6 & 5 & 15 & 19 & 3 & 3 & 3 & 0 & 0 & 0 & 0 \\
\hline E2 & 32 & 66 & 106 & 63 & 2 & 3 & 12 & 26 & 9 & 14 & 9 & 1 & 2 & 2 & 0 \\
\hline E3 & 63 & 136 & 217 & 129 & 8 & 8 & 27 & 45 & 12 & 17 & 12 & 1 & 2 & 2 & 0 \\
\hline$F_{1}$ & 42 & 101 & 184 & 97 & 6 & 6 & 37 & 38 & 6 & 12 & 6 & 0 & 1 & 3 & 2 \\
\hline $\mathrm{F} 2$ & 38 & 91 & 167 & 75 & 6 & 11 & 37 & 38 & 11 & 21 & 11 & 0 & 1 & 4 & 5 \\
\hline F3 & 80 & 192 & 351 & 172 & 12 & 17 & 74 & 76 & 17 & 33 & 17 & 0 & 2 & 7 & 7 \\
\hline G1 & 50 & 27 & 47 & 24 & 0 & 0 & 8 & 15 & 43 & 66 & 40 & 2 & 1 & 12 & 11 \\
\hline G2 & 54 & 48 & 63 & 47 & 1 & 0 & 8 & 7 & 31 & 42 & 31 & 0 & 0 & 4 & 7 \\
\hline G3 & 104 & 75 & 110 & 71 & 1 & 0 & 16 & 22 & 74 & 108 & 71 & 2 & 1 & 16 & 18 \\
\hline $\mathrm{H}_{1}$ & 46 & 25 & 28 & 24 & 0 & 0 & 0 & 4 & 36 & 53 & 31 & 2 & 2 & 10 & 8 \\
\hline $\mathrm{H} 2$ & 57 & 23 & 32 & 21 & 1 & 0 & 3 & 7 & 70 & 118 & 66 & 1 & 4 & 26 & 21 \\
\hline $\mathrm{H} 3$ & 103 & 48 & 60 & 45 & 1 & 0 & 3 & 11 & 106 & 179 & 97 & 3 & 6 & 36 & 29 \\
\hline 11 & 33 & 69 & 117 & 57 & 7 & 13 & 19 & 21 & 14 & 20 & 14 & 0 & 1 & 2 & 3 \\
\hline 12 & 38 & 103 & 161 & 85 & 8 & 18 & 22 & 28 & 12 & 27 & 12 & 0 & 4 & 5 & 6 \\
\hline 13 & 71 & 172 & 278 & 142 & 15 & 31 & 41 & 49 & 26 & 47 & 26 & 0 & 5 & 7 & 9 \\
\hline J1 & 36 & 117 & 218 & 95 & 8 & 21 & 53 & 41 & 8 & 14 & 8 & 1 & 0 & 3 & 2 \\
\hline J2 & 39 & 142 & 229 & 112 & 13 & 30 & 30 & 44 & 7 & 15 & 7 & 0 & 1 & 5 & 2 \\
\hline$\sqrt{3}$ & 75 & 259 & 447 & 207 & 21 & 51 & 83 & 85 & 15 & 29 & 15 & 1 & 1 & 8 & 4 \\
\hline K1 & 44 & 28 & 33 & 25 & 0 & 2 & 3 & 3 & 65 & 89 & 60 & 0 & 5 & 11 & 13 \\
\hline $\mathrm{K} 2$ & 48 & 63 & 89 & 62 & 0 & 1 & 9 & 17 & 112 & 171 & 109 & 3 & 9 & 21 & 29 \\
\hline K3 & 92 & 91 & 122 & 87 & 0 & 3 & 12 & 20 & 177 & 260 & 169 & 3 & 14 & 32 & 42 \\
\hline L1 & 43 & 6 & 13 & 5 & 1 & 2 & 4 & 1 & 90 & 135 & 86 & 5 & 3 & 21 & 20 \\
\hline L2 & 38 & 23 & 31 & 22 & 1 & 2 & 2 & 4 & 108 & 172 & 103 & 2 & 4 & 34 & 29 \\
\hline L3 & 81 & 29 & 44 & 27 & 2 & 4 & 6 & 5 & 198 & 307 & 189 & 7 & 7 & 55 & 49 \\
\hline
\end{tabular}

redução real na incidência de cáries dentais em áreas com e sem flúor na água de consumo, podendo o método ser considerado seguro por não ocasionar reacões tóxicas imediatas ou mediatas nas crianças;

b) o método mostrou ser de fácil utilização, prático e contou com boa aceitação tanto das crianças e de seus pais, quanto por parte da escola devido à sua limitada interferência nas atividades de ensino apenas duas vezes no ano;

c) o custo reduzido, entre US $\$ 0.10$ e US\$ 0.15 por criança, torna possivel cobrir grandes grupos com regularidade, o que viabiliza a realização de ações preventivas dentro das limitadas disponibilidades financeiras que em geral pre- 
Tabela 11. Distribuição das superficies cariadas e obturadas segundo a face atacada $e$ o grupo. Distrito Federal, 1991.

\begin{tabular}{|c|c|c|c|c|c|c|c|c|c|c|c|c|c|c|c|}
\hline \multicolumn{16}{|c|}{ Coleta 2} \\
\hline \multirow[t]{3}{*}{ Grupo } & \multirow{3}{*}{$\begin{array}{l}N^{0} \text { de } \\
\text { pessoas } \\
\text { exami- } \\
\text { nadas }\end{array}$} & \multicolumn{7}{|c|}{ Superficies cariadas (código 1) } & \multicolumn{7}{|c|}{ Supertlcies obturadas ( $\infty$ digo 2) } \\
\hline & & \multicolumn{2}{|c|}{ Número Total } & \multirow{2}{*}{$\begin{array}{l}\text { Face } \\
\text { Oclusal }\end{array}$} & \multirow{2}{*}{$\begin{array}{l}\text { Face } \\
\text { Distal }\end{array}$} & \multirow{2}{*}{$\begin{array}{l}\text { Face } \\
\text { Mesial }\end{array}$} & \multirow{2}{*}{$\begin{array}{l}\text { Face } \\
\text { Vestib. }\end{array}$} & \multirow{2}{*}{$\begin{array}{c}\text { Face } \\
\text { Palatino/ } \\
\text { lingual }\end{array}$} & \multicolumn{2}{|c|}{ Número Total } & \multirow{2}{*}{$\begin{array}{c}\text { Face } \\
\text { Oclusal }\end{array}$} & \multirow{2}{*}{$\begin{array}{l}\text { Face } \\
\text { Distal }\end{array}$} & \multirow{2}{*}{$\begin{array}{c}\text { Face } \\
\text { Mesial }\end{array}$} & \multirow{2}{*}{$\begin{array}{l}\text { Face } \\
\text { Vestib. }\end{array}$} & \multirow{2}{*}{$\begin{array}{c}\text { Face } \\
\text { Palatino/ } \\
\text { lingual }\end{array}$} \\
\hline & & Dentes & Superf. & & & & & & Dentes & Superf. & & & & & \\
\hline A1 & 46 & 65 & 110 & 64 & - & 1 & 25 & 20 & 3 & 5 & 3 & - & - & 2 & $\cdot$ \\
\hline$A 2$ & 35 & 49 & 75 & 44 & 1 & 2 & 12 & 17 & 13 & 15 & 9 & $\cdot$ & $\cdot$ & 1 & 5 \\
\hline$A 3$ & 81 & $\$ 14$ & 185 & 108 & 1 & 3 & 37 & 37 & 16 & 20 & 12 & $\cdot$ & $\cdot$ & 3 & 5 \\
\hline B1 & 32 & 35 & 44 & 32 & 1 & - & 4 & 7 & 3 & 3 & 3 & - & - & - & - \\
\hline B2 & 34 & 30 & 43 & 24 & . & . & 10 & 9 & 11 & 17 & 11 & - & - & 2 & 4 \\
\hline $\mathrm{B} 3$ & 66 & 65 & 87 & 56 & 1 & - & 14 & 16 & 14 & 20 & 14 & - & - & 2 & 4 \\
\hline $\mathbf{C}_{1}$ & 51 & 38 & 57 & 37 & - & 4 & 8 & 8 & 10 & 15 & 10 & - & - & 3 & 2 \\
\hline $\mathrm{C} 2$ & 47 & 57 & 88 & 54 & - & 2 & 19 & 13 & 23 & 31 & 23 & - & 1 & 4 & 3 \\
\hline $\mathrm{C3}$ & 98 & 95 & 145 & 91 & - & 6 & 27 & 21 & 33 & 46 & 33 & - & 1 & 7 & 5 \\
\hline D1 & 40 & 37 & 56 & 34 & - & 1 & 12 & 9 & 2 & 3 & 2 & - & - & - & 1 \\
\hline $\mathrm{D} 2$ & 44 & 56 & 89 & 53 & 2 & 3 & 15 & 16 & 1 & 1 & 1 & - & - & - & - \\
\hline $\mathrm{D} 3$ & 84 & 93 & 145 & 87 & 2 & 4 & 27 & 25 & 3 & 4 & 3 & - & - & - & 1 \\
\hline$E_{1}$ & 31 & 90 & 156 & 81 & 10 & 12 & 20 & 33 & 3 & 3 & 3 & - & - & - & - \\
\hline E2 & 32 & 82 & 132 & 75 & 1 & 8 & 15 & 33 & 16 & 24 & 16 & 1 & 3 & 2 & 2 \\
\hline E3 & 63 & 172 & 288 & 156 & 11 & 20 & 35 & 66 & 19 & 27 & 19 & 1 & 3 & 2 & 2 \\
\hline F1 & 42 & 99 & 153 & 95 & 4 & 5 & 21 & 28 & 15 & 24 & 15 & 1 & - & 4 & 4 \\
\hline F2 & 38 & 95 & 159 & 80 & 7 & 13 & 28 & 31 & 20 & 32 & 20 & - & 1 & 5 & 6 \\
\hline F3 & 80 & 194 & 312 & 175 & 11 & 18 & 49 & 59 & 35 & 56 & 35 & 1 & 1 & 9 & 10 \\
\hline $\mathrm{G}_{1}$ & 50 & 33 & 51 & 26 & 1 & - & 9 & 13 & 63 & 104 & 60 & 5 & 1 & 21 & 17 \\
\hline G2 & 54 & 64 & 89 & 62 & 1 & 3 & 13 & 10 & 62 & 90 & 61 & . & 3 & 12 & 14 \\
\hline G3 & 104 & 97 & 140 & 88 & 2 & 3 & 22 & 23 & 125 & 194 & 121 & 5 & 4 & 33 & 31 \\
\hline $\mathrm{H}_{1}$ & 46 & 32 & 44 & 32 & - & . & 4 & 8 & 46 & 66 & 45 & 2 & - & 11 & 8 \\
\hline $\mathrm{H} 2$ & 57 & 27 & 41 & 25 & 3 & - & 6 & 7 & 101 & 168 & 95 & $\overline{6}$ & 8 & 32 & 27 \\
\hline $\mathbf{H 3}$ & 103 & 59 & 85 & 57 & 3 & - & 10 & 15 & 147 & 234 & 140 & 8 & 8 & 43 & 35 \\
\hline 11 & 33 & 105 & 172 & 87 & 12 & 14 & 25 & 34 & 23 & 37 & 23 & 2 & 2 & 5 & 5 \\
\hline 12 & 38 & 137 & 212 & 110 & 14 & 24 & 25 & 39 & 13 & 26 & 13 & 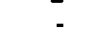 & 3 & 5 & 5 \\
\hline 13 & 71 & 242 & 384 & 197 & 26 & 38 & 50 & 73 & 36 & 63 & 36 & 2 & 5 & 10 & 10 \\
\hline J1 & 36 & 130 & 223 & 108 & 12 & 19 & 40 & 44 & 16 & 26 & 11 & 1 & 4 & 3 & 7 \\
\hline J2 & 39 & 149 & 223 & 118 & 13 & 29 & 21 & 42 & 16 & 32 & 16 & 1 & 2 & 7 & 6 \\
\hline J3 & 75 & 279 & 446 & 226 & 25 & 48 & 61 & 86 & 32 & 58 & 27 & 2 & 6 & 10 & 13 \\
\hline K1 & 44 & 10 & 12 & 9 & - & - & 2 & 1 & 98 & 139 & 94 & - & 5 & 20 & 20 \\
\hline K2 & 48 & 33 & 37 & 33 & - & - & 2 & 2 & 179 & 284 & 177 & 5 & 10 & 41 & 51 \\
\hline K3 & 92 & 43 & 49 & 42 & - & - & 4 & 3 & 277 & 423 & 271 & 5 & 15 & 61 & 71 \\
\hline L1 & 43 & 10 & 18 & 9 & 1 & 2 & 4 & 2 & 97 & 154 & 94 & 7 & 5 & 25 & 23 \\
\hline L2 & 38 & 18 & 38 & 27 & 1 & 2 & 2 & 6 & 136 & 206 & 128 & 3 & 6 & 35 & 34 \\
\hline L3 & 81 & 28 & 56 & 36 & 2 & 4 & 6 & 8 & 233 & 360 & 222 & 10 & 11 & 60 & 57 \\
\hline
\end{tabular}

valecem nos programas públicos de assistência odontológica no país;

d) a concentração das aplicações tópicas em curtos periodos semestrais libera as unidades de atenção odontológica para que, no dia a dia, dediquem-se ao trabalho educativo, à prestação de cuidados clínicos básicos e ao apoio e controle do uso de outros métodos preventivos como a ingestão de água fluoretada e a escovação dental com dentifrícios fluoretados.

Duas recomendaçōes finais parecem ser de utilidade prática:

a) Os resultados obtidos no presente artigo apontam para a necessidade de novos e mais apro- 
fundados estudos sobre a eficácia e a eficiência do método no país, sugerindo-se especialmente análises nas áreas de abrangência local/ municipal do Sistema Único de Saúde e com maior tempo de duração ( 2 a 3 anos, possivelmente em áreas não sujeitas a migração intensiva), incluindo comparaçōes com outros métodos alêm de pesquisas de opinião da população.

b) Cada programa de saúde bucal ou de assistência odontológica, a qualquer nível, deve desenvolver uma ação preventiva permanente e sem solução de continuidade de forma a abranger o maior número possível de crianças em idade escolar. Para tanto, ao programa compete assumir os custos envolvidos, adquirindo os insumos preventivos da mesma maneira como o faz em relação ao material de uso curativo. Ações preventivas coletivas como as demonstradas no presente estudo, ou que empreguem métodos alternativos similares, são econômica e operacionalmente viáveis nas condições práticas do país e podem contribuir fortemente para aliviar os sofrimentos da população por causas odontológicas e reduzir os exagerados índices de doenças bucais hoje constatados no Brasil.

\section{Agradecimentos}

A todas as crianças que participaram do estudo, bem como a seus pais pela concordância e estímulo. À direção e ao professorado das várias escolas envolvidas pelo apoio recebido; à equipe examinadora que desenvolveu todo o trabalho de campo composta pelos cirurgiōes-dentistas Eliana David Ribeiro, Marcos Miziara, Maria do Socorro Mendeiros, e pelos técnicos de higiene dental Cleusa Gonçalves de Souza, Laura Augusto da Silva, Maria Amélia Carvalho Miranda, Maria Goretti C. Rodrigues e Maria Lenice da Silva Avelar; ao Dr. Vitor Gomes Pinto pela orientação técnica e pelas análises estatísticas; ao Dr. Sergio Pereira, chefe da Seção de Saúde Escolar da Fundação Educacional do DF, pelas condições oferecidas para a viabilização do estudo.

PINTO, I. L. [Dental caries prevention through APF Gel-Tray applications each six months]. Rev. Saúde Pública, 27: 277-90, 1993. 998 children aged 6, 8 and 10 , from low income families living in the Federal District, Brazil and attending public, first grade, schools, received bi-annual topical APF Gel-Tray applications. The mass methodology proposed by the National Dental Caries Preventive Program of the Brazilian Ministry of Health, without previous prophylaxis, was adopted. After one year, in fluoridated communities the reduction in the incidence of CPOS was of $31.6 \%, 24.9 \%$ and $39.5 \%$, respectively, for the groups aged 6,8 and 10 . In non fluoridated communities the reductions were, respectively, of $24.3 \%, 26.6 \%$ and $27.7 \%$, in every case with statistic significance at the $95 \%$ confidence level. Considering the positive results in a developing area, it is recommended that oral health institutions at all levels could adopt a comprehensive and continuous preventive program for children under their responsibility.

Keywords: Fluoridades topical. Dental caries, prevention. Dental Health surveys.

\section{Referências Bibliográficas}

1. BIJELLA, M.F.T.B. Comparison of dental prophylaxis and tooth brushing prior to topical APF application. Community Dent. Oral Epidemiol., 13: 208-11, 1985.

2. BRYAN, E.T. \& WILLIAMS, J.E. The cariostatic effectiveness of a phosphate-fluoride gel administered annually to school children: final results. J. Public Health Dent., 30: 13-6, 1970.

3. COBB, B.H.:ROZIER, G.R.; BAWDEN, J.W. A clinical study of the caries preventive effects of an APF solution and an APF thixotropic gel. Pediatr. Dent., 2: 263. $6,1980$.

4. COMPANHIA DE ÁGUA E ESGOTOS DE BRASILIA. Ofício 011/90 sobre adição de flúor nas águas de abastecimento do Distrito Federal. Brasília, 1990.

5. DEPARTAMENT OF NATIONAL HEALTH AND WELFARE. Preventive dental services. 2 ed. Ottawa, 1988.

6. HOUPT, M.; KOENISBERG, S.; SHEY, Z. The effect of prior tooth cleaning on the efficacy of tropical fluoride treatment: two-year results. Clin. Prev. Dent., 5: 8-10, 1983.

7. NGGRAHAM, R.Q. \& WILLIAMS, J.E. An evaluation of the utility of applications and cariostatic effectiveness of phosphate-fluorides in solution and gel states. $J$. Tenn. Dent. Ass., 50: 5-12, 1970.

8. KATZ, R.V.; MESKIN, L.H.; JENSEN, M.E.; KELLER, D. Topical fluoride and prophylaxis: a 30 month clinical trial. J. Dent. Res., 63 (Spec issue Abstracts 771): 256,1984 .

9. LARSEN, M.J.; KIRKEGARD, E.; FEJERSKOV, O.; POULSEN, S. Prevalence of dental fluorosis after fluoride-gel treatments in a low -fluoride area. J. Dent. Res., 64: 1076-8, 1985.

10. LECOMPTE, E.J. Clinical application of topical fluoride products: risks, benefits, and recommendations. J. Dent . Res., 66: 1066-71, 1987.

11. MELBERG, J. R.; FRANCHI, G. J.; ENGLANDER, H. R.; MOSLEY, G. W.; NICHOLSON, C. R. Short intensive topical APF applications and dental caries in a fluoridated area. Community Dent. Oral Epidemiol., 6: 117 $20,1978$.

12. MINISTÉRIO DA SAÚDE. Divisão Nacional de Saúde Bucal. Aplicação tópica de flúor com gel fluoretado: normas técnicas. Brasília, 1989.(Documentos Técnicos, 04).

13. MINTSTÉRIO DA SAUDE. Divisão Nacional de Saúde Bucal. Levantamento epidemiológico em saúde bucal: Brasil zona urbana,1986. Brasilia, 1988. (Série Estudos e Projetos, 04).

14. MINISTERIO DA SAỨDE. Divisão Nacional de Saúde Bucal. Programa nacional de prevenção da cárie dental-PRECAD. Brasília, 1989. (Documentos Técni- 
15. NEWBRUN, E. Topical fluoride therapy: discussion of some aspects of toxicology, safety, and efficacy. $J$. Dent. Res. , 66:1084-6,1987.

16. PINTO, V. G. A questão epidemiológica e a capacidade de resposta dos serviços de saúde bucal no Brasil. São Pau1o, 1992. [Tese de Doutorado - Faculdade de Saúde Pública da USP].

17. PINTO, V.G. Saúde bucal, odontologia social e preventiva. 3 ed. São Paulo, Ed. Santos, 1992.

18. RIPA, L.W. An evaluation of the use of professional (operator-applied) topical fluorides. J. Dent. Res., 69: 786$96,1990$.

19. RIPA, L.W. Topical fluorides: a discussion of risks and benefits. J. Dent. Res., 66: 1079-83, 1987.

20. RIPA, L.W.; LESKE, G. S.; SPOSATO, A.; VARMA, A. Effect of prior toothcleaning on biannual professional APF topical fluoride gel-tray treatments: results after two years. Clin. Prev. Dent. , 5: 3-7, 1983.

21. RIPA, L.W.; LESKE, G.S.; SPOSATO, A.; VARMA, A.
Effect of prior toothcleaning on biannual professional APF topical fluoride gel-tray treatment: results after three years. Caries Res., 18: 457-64, 1984.

22. SATO, S. Aspectos preventivos do desenvolvimento da den. tição permanente: manual ilustrado. São Paulo, Ed. Santos, 1991.

23. SECRETARIA DE EDUCAÇĀO. Fundação Educacional do Distrito Federal. Programa integrado de saúde esco. lar-PISE: projeto 1992/1994. Brasilia. Departamento de Pedagogia, DAE/SSE 1992.

24. WORLD HEALTH ORGANIZATION. Oral health sur. veys: basic methods. 2 ed. Geneva, 1977.

25. WORD HEALTH ORGANIZATION. Oral health global indicator for 2.000; dental caries levels at 12 years. Geneva, 1991.

Recebido para publicação em 20.8 .1992 Reapresentado em 26.3.1993 Aprovado para publicação em 9.6.1993 